\title{
In-Situ Optical Monitoring of Electrochemical Copper Deposition Process for Semiconductor Interconnection Technology
}

\author{
Sang Jeen Hong ${ }^{\dagger}$, Li Wang, and Dongsun Seo \\ Department of Electronic Engineering, Myongji University, Yongin 449-728, Korea \\ Tae-Sik Yoon \\ Department of Material Science Engineering, Myongji University, Yongin 449-728, Korea
}

Received November 8, 2011; Revised January 21, 2012; Accepted February 7, 2012

\begin{abstract}
An in-situ optical monitoring method for real-time process monitoring of electrochemical copper deposition (CED) is presented. Process variables to be controlled in achieving desired process results are numerous in the CED process, and the importance of the chemical bath conditions cannot be overemphasized for a successful process. Conventional monitoring of the chemical solution for CED relies on the $\mathrm{pH}$ value of the solution, electrical voltage level for the reduction of metal cations, and gravity measurement by immersing sensors into a plating bath. We propose a nonintrusive optical monitoring technique using three types of optical sensors such as chromatic sensors and UV/VIS spectroscopy sensors as potential candidates as a feasible optical monitoring method. By monitoring the color of the plating solution in the bath, we revealed that optically acquired information is strongly related to the thickness of the deposited copper on the wafers, and that the chromatic information is inversely proportional to the ratio of $\mathrm{Cu}$ (111) and $\{C u(111)+C u(200)\}$, which can used to measure the quality of the chemical solution for electrochemical copper deposition in advanced interconnection technology.
\end{abstract}

Keywords: Electrochemical copper deposition, In-situ monitoring, Copper interconnection

\section{INTRODUCTION}

Copper $(\mathrm{Cu})$ has been an alternative to aluminum $(\mathrm{Al})$ or $\mathrm{Al}(\mathrm{Cu})$ as a semiconductor interconnection material because of its better electrical conductivity, which provides improved device functionality and product reliability. Copper is not only superior with respect to electromigration resistance, but also in compatibility with conventional multi-layer interconnection in frontend-of-line (FEOL) and back-end-of-line (BEOL) processes, and has been recognized as a practical interconnection material in the semiconductor and microelectronics packaging industries

${ }^{\dagger}$ Author to whom all correspondence should be addressed: E-mail: samhong@mju.ac.kr

Copyright $\odot 2012$ KIEEME. All rights reserved. This is an open-access article distributed under the terms of the Creative Commons Attribution Non-Commercial
License (httr:///creativecommons.org/licenses $/$ by-nc/3.0) which permits unrestricted noncommercial use, License (http:///creativecommons.org/licenses/by-nc/3.0) which permits unrestricted
distribution, and reproduction in any medium, provided the original work is properly cited.
[1,2]. Forming of $\mathrm{Cu}$ thin film can be done by either dry or wet processes. Physical vapor deposition (PVD) and chemical vapor deposition (CVD) of copper forms high quality metallization, and is rather useful for the formation of single metal lines due to limited step coverage and filling capability, which is known as a void or key-hole in via-filling processes. "Wet" deposition methods can be either electroless or electrolytic, depending on whether the copper is electrically assisted or chemically assisted. Terminology for these wet processes varies in their usage, but we prefer to use the term electrochemical deposition over electroplating since the process is electrically assisted in a chemical bath (electrochemical) and involves filling vias instead of covering entire surfaces.

The $\mathrm{Cu}$ dual-damascene process allows reduced process integration of multi-layer metal interconnection by $30 \%$ with respect to conventional BEOL interconnection. $\mathrm{Cu}$ through-silicon-vias (TSVs) are able to overcome some limitations with respect to 


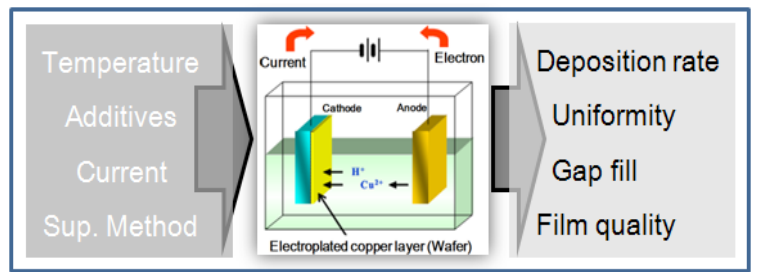

Fig. 1. Process input parameters and the responses of interest.

Moore's law by stacking chips vertically. Thus, copper interconnection has already assumed an important role in semiconductor device and packaging manufacturing.

A number of variables must be considered in the electrochemical deposition of copper, such as seed layer coverage, base and additive chemistries, electrical power supply waveforms, temperature, humidity, and others. In the early stages of process development, PCB-based process chemistry was expanded to optimize the electrochemical deposition process for applying dual-damascene interconnection technology to advanced semiconductor fabrication [3]. During this time, a group of researchers at Stanford reported several findings: 1) electromigration lifetime of (111) CVD Cu is about four times longer than that of (200) $\mathrm{CVD} \mathrm{Cu} ; 2)$ the texture and the grain structure are critical factors that determine the electromigration lifetime of $\mathrm{Cu}$ interconnects; 3) (111) texture is desirable for electrical conductivity; 4) the grain structure of $\mathrm{Cu}$ is highly dependent on the deposition technique; and 5) electroplating is more desirable than CVD for deep submicron $\mathrm{Cu}$ metallization because of larger gains that result in improved electromigration reliability [4]. Later, Feng and et. al. reported that a ratio of (111)/(200) between the amount of $\mathrm{Cu}$ and the impurities in an electroplated $\mathrm{Cu}$ film was strongly related to the formation of void defects [5]. They also showed a significantly decreased number of void defects in pulse-reverse current.

In electrochemical deposition processes, the type and flow of the current source are known to be important factors for achieving desired film quality. However, bath chemistry including additives and impurities adds complexity to wet deposition process control. The simplified process inputs and responses of interest are illustrated in Fig. 1. To achieve successful $\mathrm{Cu}$ electrochemical deposition in a semiconductor interconnection process, it is desirable to monitor how impurities or by-products in the bath chemistry affect the oxidation/reduction reactions of the plating additives. The concentrations of the electroplating bath components were monitored using on-line bath metrology of inorganic compounds $\left(\mathrm{Cu}^{2+}, \mathrm{H}_{2} \mathrm{SO}_{4}\right.$, and $\left.\mathrm{Cl}\right)$ and off-line analytical techniques employing high performance liquid chromatography (HPLC) [6]. Recently, electrochemical impedance spectroscopy (EIS) was performed on $\mathrm{Cu}$ interconnect plating baths during deposition to investigate the degradation of bath [7]. Although the chemical compositions of the additives and impurities were not identified by EIS, the presence and interaction of the additives and impurities in the aged bath was revealed employing process monitoring techniques. More recently, a group of industrial researchers in Japan identified the degradation of the bath in terms of the increase of a by-product which caused increased void formation and interconnection failure in the via-hole filling process, which they confirmed with HPLC measurement $[7,8]$. Virtual metrology (VM) modeling for fault detection and classification (FDC) with in-situ process monitoring technique using engineering equipment system (EES) data was effective in enhancing the process quality without increasing the manufacturing cost due to additional inspection. It is also suggested that advanced process control (APC) is beneficial for continuous con- trol of effluence and replenishment in plating baths [9].

The objective of this paper is to facilitate the VM-APC by investigating optical transmittance spectroscopy (OTS) data from wet plating baths for the feasibility of real-time in-situ optical monitoring in the electrochemical copper deposition process. In this research, we practiced an optical non-invasive monitoring technique using three types of optical monitoring tools: chromatic sensors, UV/VIS spectroscopy, and near infra-red (NIR) spectroscopy. The motivation for the suggested optical monitoring technique originated from well-established in-situ plasma process monitoring methods. A chromatic monitoring sensor was used for real-time monitoring of the chamber arcing in the plasma etch process; UV/VIS spectroscopy, known as optical emission spectroscopy, has been used for real-time monitoring for malfunction diagnosis in plasma etch equipment [10]; and NIR spectroscopy measurement was used for real-time monitoring of the etching solutions [11]. The capability of chromatic monitoring of electrochemical copper deposition processes in advanced semiconductor manufacturing has been successfully demonstrated.

Section II illustrates the experimental apparatus and process mechanism, and Section III presents the in-situ real-time monitoring technique with the acquired data analysis. A correlation study with surface analysis results for the in-situ data is provided in Section IV, followed by the conclusion.

\section{EXPERIMENTAL APPARATUS}

\subsection{Electrochemical deposition process}

Electrochemical deposition, also known as electroplating, is the deposition of a metal film onto an object by applying a negative charge to the object and immersing it into a solution that contains a metal salt. The metal salt contains positively charged metal ions which are attracted to the negatively charged object. Simple electroplating is a common school project that involves plating a copper coin with either copper or nickel. Positively charged polyatomic ions (cations) move to the cathode while negatively charged polyatomic ions (anions) move to the anode as a result of the conversion between electrical and chemical energy. When external electrical energy is provided, the metal at the anode is oxidized from the zero-valence state into cations and dissolves into the electrolyte. The cations are reduced at the cathode by depositing and settling to a metallic, zero-valence state.

In electrochemical copper deposition, copper is oxidized at the anode into $\mathrm{Cu}^{2+}$ by losing two electrons and dissolved into a copper sulfate $\left(\mathrm{CuSO}_{4} 5 \mathrm{H}_{2} \mathrm{O}\right)$ solution. The two electrons lost are transported to the cathode by electrical potential. At the cathode, the $\mathrm{Cu}^{2+}$ is reduced to metallic copper by gaining two electrons.'

The electrolyte is a copper sulfate solution;

$$
\mathrm{CuSO}_{4} \stackrel{\text { hydrolyze }}{\longrightarrow} \mathrm{Cu}^{2+}+\mathrm{SO}_{4}^{2-}
$$

At the cathode (wafer), either $\mathrm{H}_{2} \mathrm{O}$ or $\mathrm{Cu}^{2+}$ could undergo reduction;

$$
\begin{aligned}
& \mathrm{Cu}^{2+}+2 e^{-} \longrightarrow \mathrm{Cu}_{(S)} \\
& 2 \mathrm{H}_{2} \mathrm{O}+2 e^{-} \longrightarrow \mathrm{H}_{2(G)}+2 \mathrm{OH}^{-}
\end{aligned}
$$

The final REDOX reactions are:

$\mathrm{Cu}^{2+}+2 e^{-} \longrightarrow \mathrm{Cu}_{(S)}$ Reduction at the cathode

$2 \mathrm{H}_{2} \mathrm{O}_{(L)} \longrightarrow \mathrm{O}_{2(G)}+4 \mathrm{H}^{+}+4 e^{-}$Oxidation at the anode 

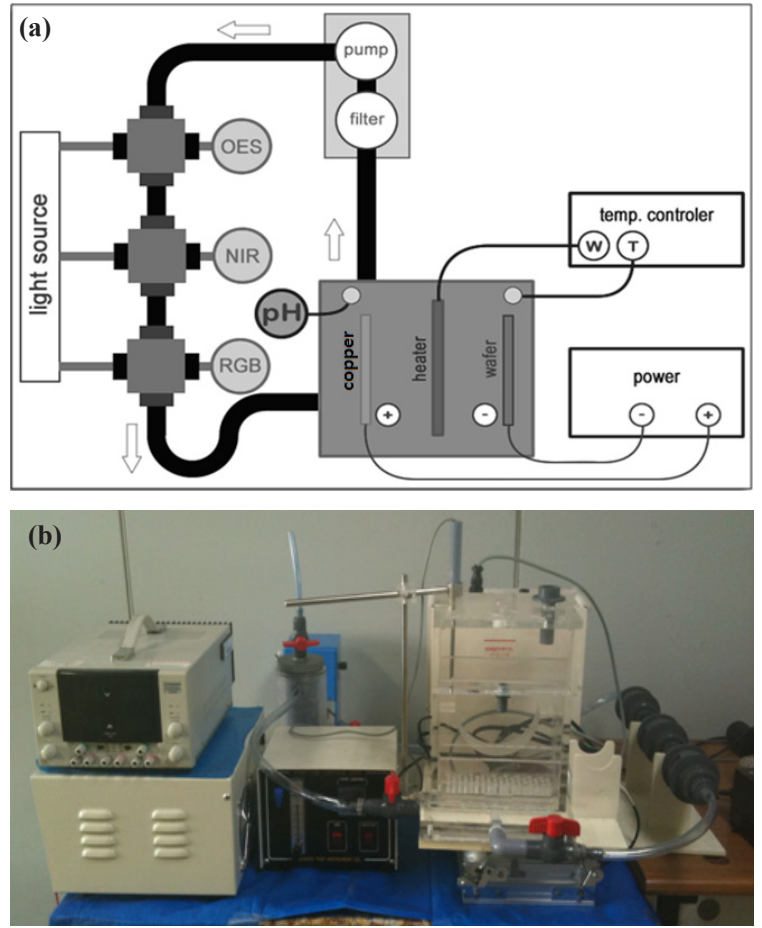

Fig. 2. Experimental apparatus for in-situ optical process monitoring.

\subsection{Experimental setup and in-situ process monitoring sensors design of experiment}

Dehydrated copper sulfate $\left(\mathrm{CuSO}_{4}\right)$ is white in color, but hydrated copper sulfate $\left(\mathrm{CuSO}_{4} 5 \mathrm{H}_{2} \mathrm{O}\right)$ appears sparkling blue. Hydrates are crystalline solids that contain a fixed number of water molecules as an integral part of their crystalline structure. The number of water molecules bounded for each metal ion can be a characteristic of the particular metal ion, which can be manifested in its color information. Since the electrochemical copper deposition process is a redox process of $\mathrm{Cu}$ ions and water, monitoring of the solution by observing its color is plausible.

A custom-built electrochemical copper deposition system is used for this experiment. The bath can hold up to 6 inches of copper source and 4 inches of wafer. No wafer rotation was performed in this experiment, but the wafer holder can be rotated with the addition of a rotating unit for improved film uniformity. Bath temperature is controlled by a tungsten heater located at the bottom of the bath housing, and an industrial $\mathrm{pH}$ meter is also installed for the purpose of conventional chemical monitoring. The speed of solution circulation is controlled by an externally located circulation pump with a filter unit for sludge filtering, and an air bubble supply is also provided at the bottom of bath to minimize the effect of localized vortices in the solution. An illustration of the experimental apparatus is presented in Fig. 2.

Three types of optical monitoring sensors are installed between the pump-out and bath-supply for optical transmittance spectroscopy (OTS). Each sensor unit is specially designed for its optical transmittance measurement with a glass cylinder type waveguide. Carefully designed optical waveguides immersed in the solution provide stable and reliable optical transmittance characteristics for in-situ chemical monitoring. The chromatic monitoring system consists of a sensor module with optical broadband detectors, a data acquisition hardware module with $1 \mathrm{~Hz}$ sampling rate, and a computer monitoring system with integrated graphic user interface (GUI) as shown in Fig. 3. Chromatic

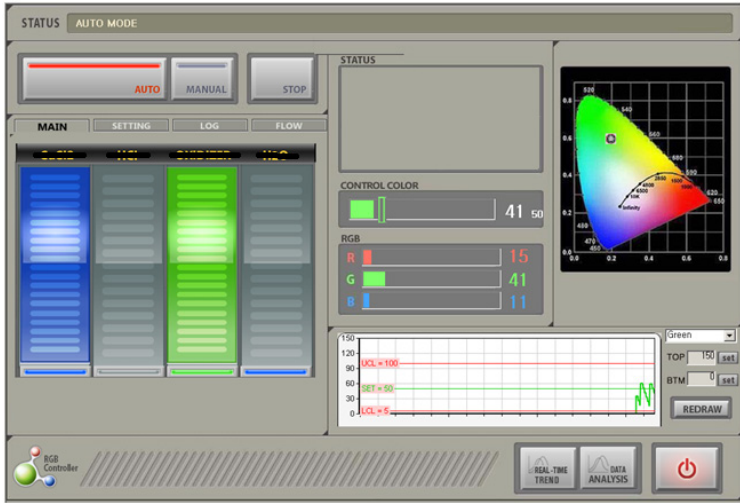

Fig. 3. Graphic user interface (GUI) of the developed chromatic monitoring system.

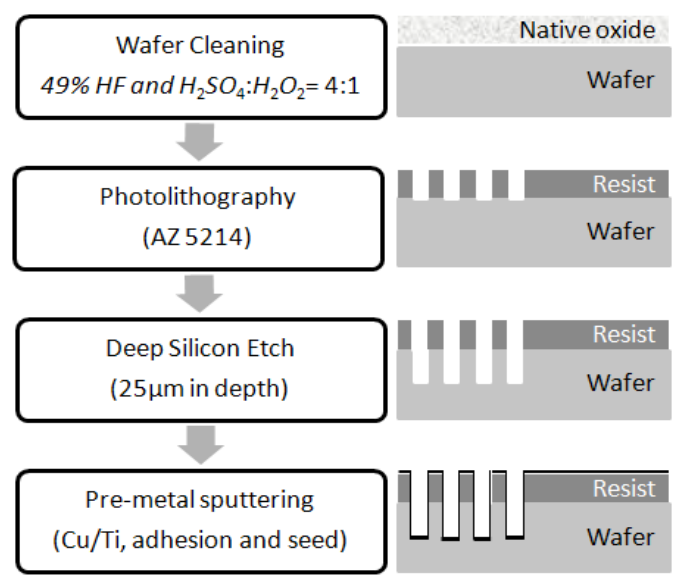

Fig. 4. Process flow for wafer sample preparation.
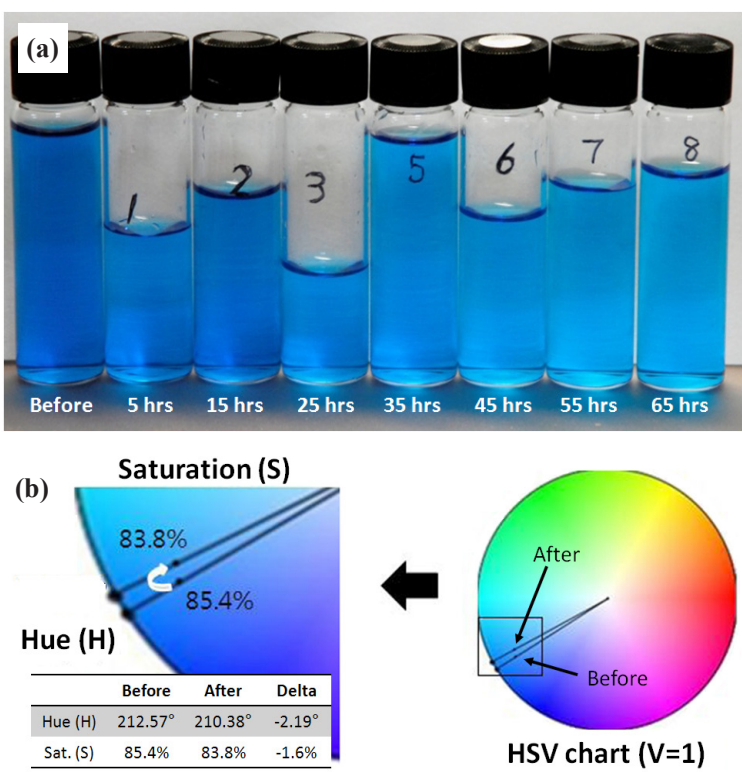

Fig. 5. HSV representations of shifted (or drifted) material's optical property.

measurement provides not only color information in red, green, and blue levels, but also hue, saturation, and value information. Although chromatic data may not present scientific analytical 

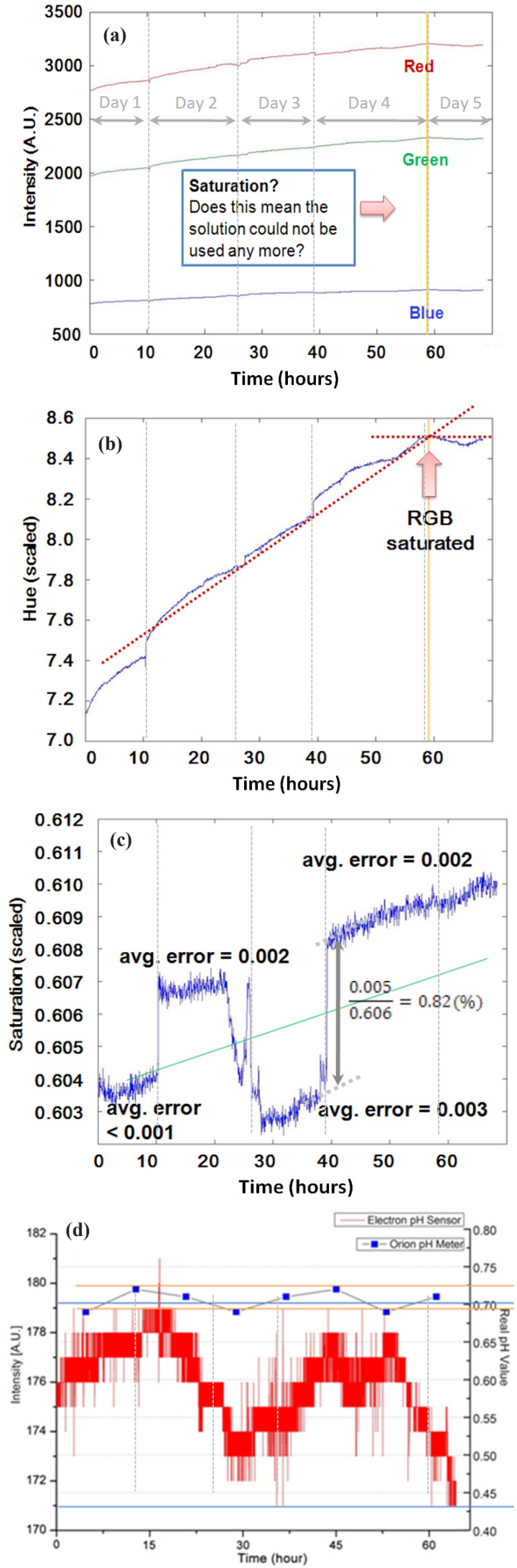

Fig. 6. Time-resolved representations of in-situ monitoring data in RGB and HSV.

information on the object being monitored directly, it is sensitive to the change of color in the chemical solution during a continu- ous electrochemical copper deposition process. Detecting shift or drift and variation in the chromatic information also supports the potential of the system as an in-situ chemical monitoring technique.

Other sensors installed are UV/VIS and NIR spectroscopy devices. UV/VIS/NIR optical absorption, transmission, and reflectance (ATR) spectroscopy are useful methods for chemical analysis of molecular aggregation, orientation, and structure [12,13]. Optical emission spectroscopy (OES) has been actively employed as an in-situ monitoring tool for plasma diagnostics and process monitoring for more than a decade $[14,15]$. Spectroscopic monitoring sensors may provide more detailed information on the object being monitored by correlating specific peaks with atomic and molecular characteristics; however, in contrast with plasma processes, chemical solutions do not emit light, thus we have included -connected high-power tungsten-halogen light sources to employ OTS. Individual sensor units are optically isolated to prevent any optical interference by waveguide effects. In addition to optical monitoring sensors, conventional $\mathrm{pH}$ measurement was also set up to record the $\mathrm{pH}$ value of the hydrated sulfate solution.

After filling the bath with $4.5 \mathrm{~L}$ of $\mathrm{CuSO}_{4}$, a series of electrochemical copper depositions on 4-inch wafers was performed without adding additional additives to the bath, and without replacement of the sulfate solution, in order to monitor bath degradation. The supplied current density was set to $20 \mathrm{~A} / \mathrm{dm}^{2}$, and the bath temperature was maintained at $30^{\circ} \mathrm{C}$ during the process. Approximately $25 \mu \mathrm{m}$-depth via-patterned wafers were prepared by silicon deep etching employing STS ICP etcher with Bosh process, and the $\mathrm{Cu} / \mathrm{Ti}$ seed layer was prepared by sputtering as shown in Fig. 4. Even though a via-filling of $25 \mu \mathrm{m}$ in depth may require hours of deposition time, we consistently reloaded new wafers every 5 minutes to tightly track the correlation of bath condition with the results from surface metrology analysis. More than 750 wafer runs were processed with four intermissions during 70 hours of this experiment, and in-situ chromatic and spectroscopy data were collected every 1 and 10 seconds, respectively. In order to more realistically approximate the volume of a manufacturing environment, 12-18 hours of daily operation was performed in three operation shifts per day. The total experiment was performed in 5 consecutive days.

\section{IN-SITU COLOR MONITORING OF PLATING BATH}

Sulfate solution was sampled every 10 hours to visually confirm our postulation of chromatic information changes in the redox process, and the collected samples are presented in Fig. 5(a). It is difficult to tell the difference between adjacent samples within 10 hours, but differences between the 3-4 samples are apparent in the figure. Converting RGB data to Hue-SaturationValue (HSV), we have observed a decrease in hue by 2.19 degrees and saturation by $1.6 \%$ as shown in Fig. 5(b). The result proves what we have visually observed from the sulfate samples. We further investigated in-situ chromatic data with regard to whether the material's optical properties were shifted or drifted over 70 hours of processing. As shown in Fig. 6(a), RGB representation shows a gradual increase in intensity of the three chromatic components, which were saturated around 58 hours. Scaled absolute values of hue and saturation are also presented in Figs. 6(b) and (c). We had the same observation as shown in RGB, and more clear saturation was observed in Hue. Figure 6(c) is shown to have a large amount of fluctuation in saturation; however, the largest fluctuation that occurred only contributes approximately $0.82 \%$ variation with respect to the baseline, and good agreement 

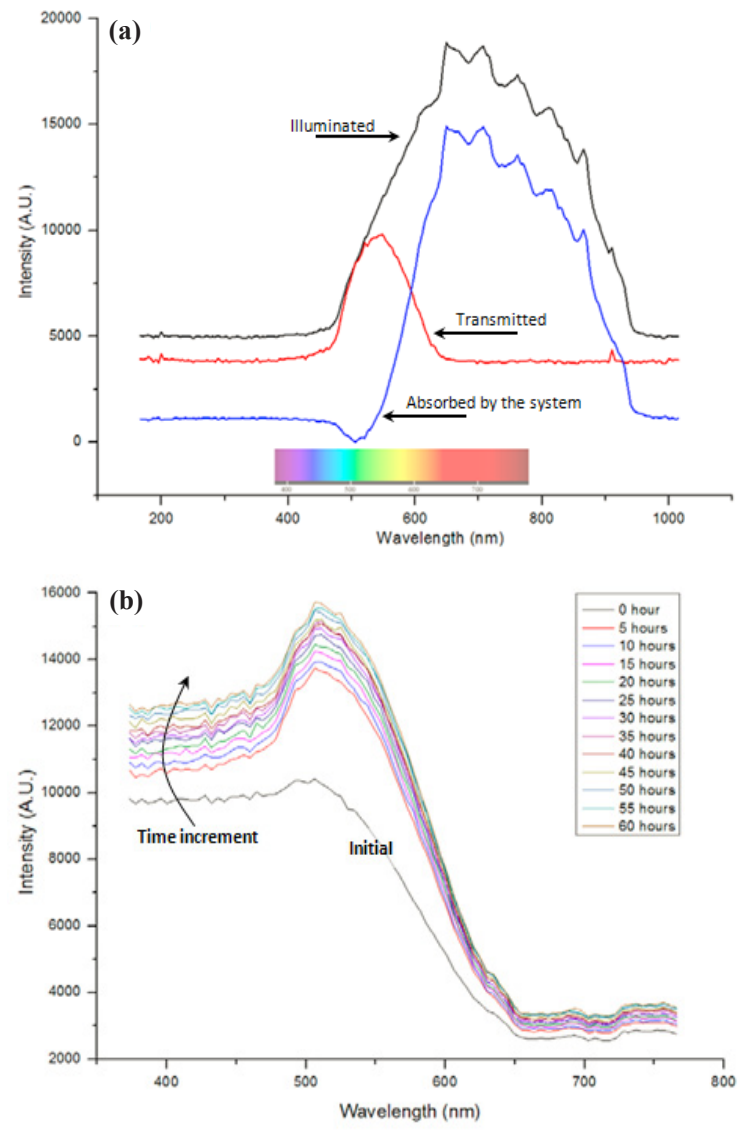

Fig. 7. Optical transmission spectroscopy (OTS) data plots.

was observed over course of the experiment. It is surprising that the chromatic intensity accurately detected every intermission of less than a half day, and it shows how chromatic monitoring can be sufficiently sensitive to the process variation. When comparing with real-time in-situ $\mathrm{pH}$ measurements and eight instances of augmented off-line $\mathrm{pH}$ measurements with Orion's bench-top pH meter, no significant anomaly in the process was observed as shown in Fig. 6(d). Further explanation of the drifted optical monitoring data with wafer metrology will be provided in the next section.

We recorded the optical transmittance spectroscopy (OTS) data from the empty system as a dark signal, and the absorbed signal was found by subtracting the acquired signal from the illuminated as shown in Fig. 7(a). UV/VIS spectroscopy data in the 350-550 $\mathrm{nm}$ wavelength range showed gradual increase along with increases in the process time, which is presented in Fig. 7 (b). This is the same observation as in the previous chromatic result. In our postulation, we expected some noticeable peaks that would correspond to the chemistry as in plasma process monitoring; unfortunately no further detailed information was found in the acquired spectroscopy data from this experiment.

\section{FILM CHARACTERIZATION}

Although in-situ real-time optical monitoring revealed and identified color changes in the hydrate sulfate during the copper deposition, a direct relationship between the color change and film quality on the wafer is still in question. To alleviate this concern, sample wafers at every 10 hours of deposition processing were analyzed by scanning electron microscopy (SEM) and X-ray
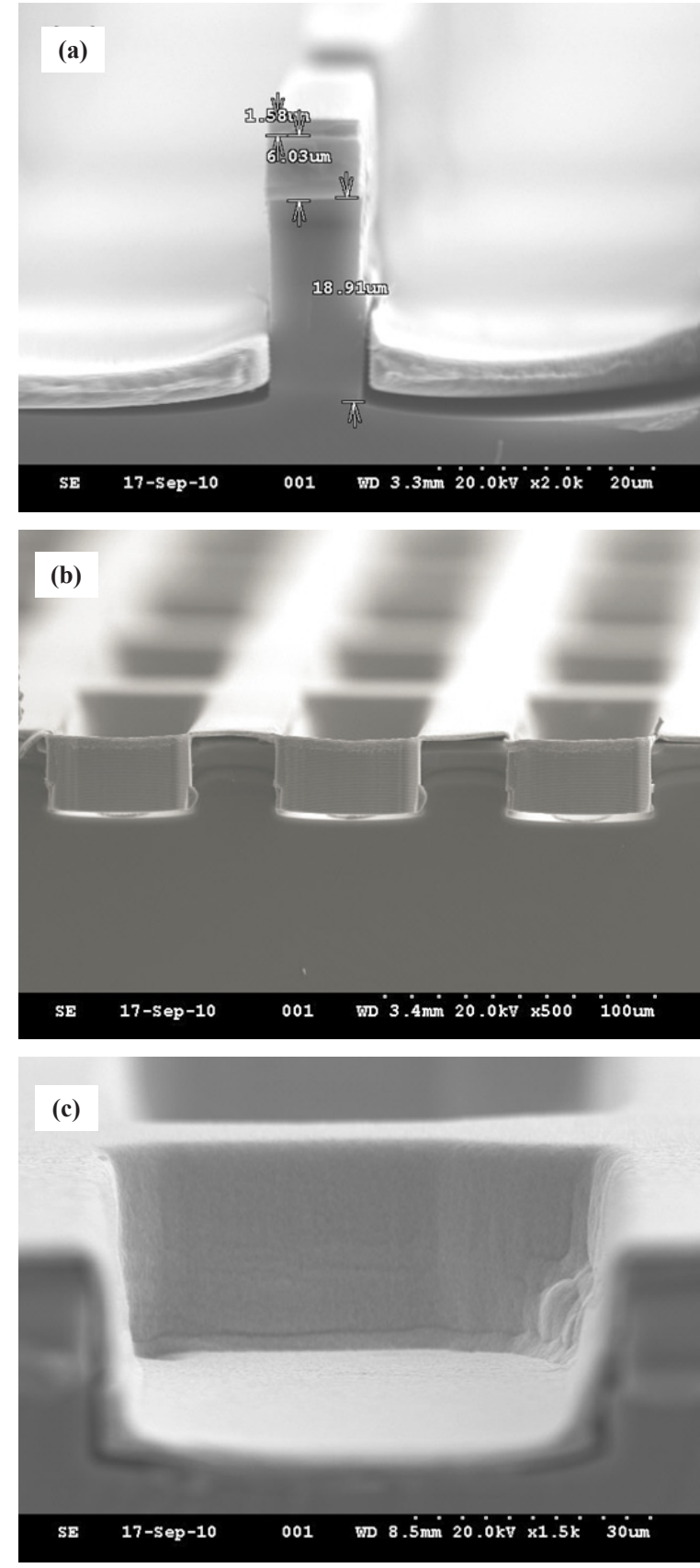

Fig. 8. SEM images of partially filled square vias: (a) sample taken at 30 hours; (b) and (c) 60 hours.

diffraction (XRD) to characterize the surface and microstructure of the film. Fig. 8(a) shows the deposited wafer sample at 30 hours with AZ 5214 photoresist mask. We can clearly see that electrochemical copper deposition was successfully performed with a thickness of $1.58 \mu \mathrm{m}$. The wafer samples employed in this experiment were continuously recycled after stripping the electroplated copper layer off due to the limited resources of a university research environment. The repeated copper stripping caused PR erosion after the third day of the experiment, but consistent electrochemical deposition was performed for real-time monitoring without a PR layer. Figures 8(b) and (c) are crosssectional SEM images of the partially filled square vias acquired at 60 hours without a PR mask layer. The cut edge in the image presents scallop patterns from the Bosch trench process, and the deposited copper is comparatively uniform. The electrochemi- 

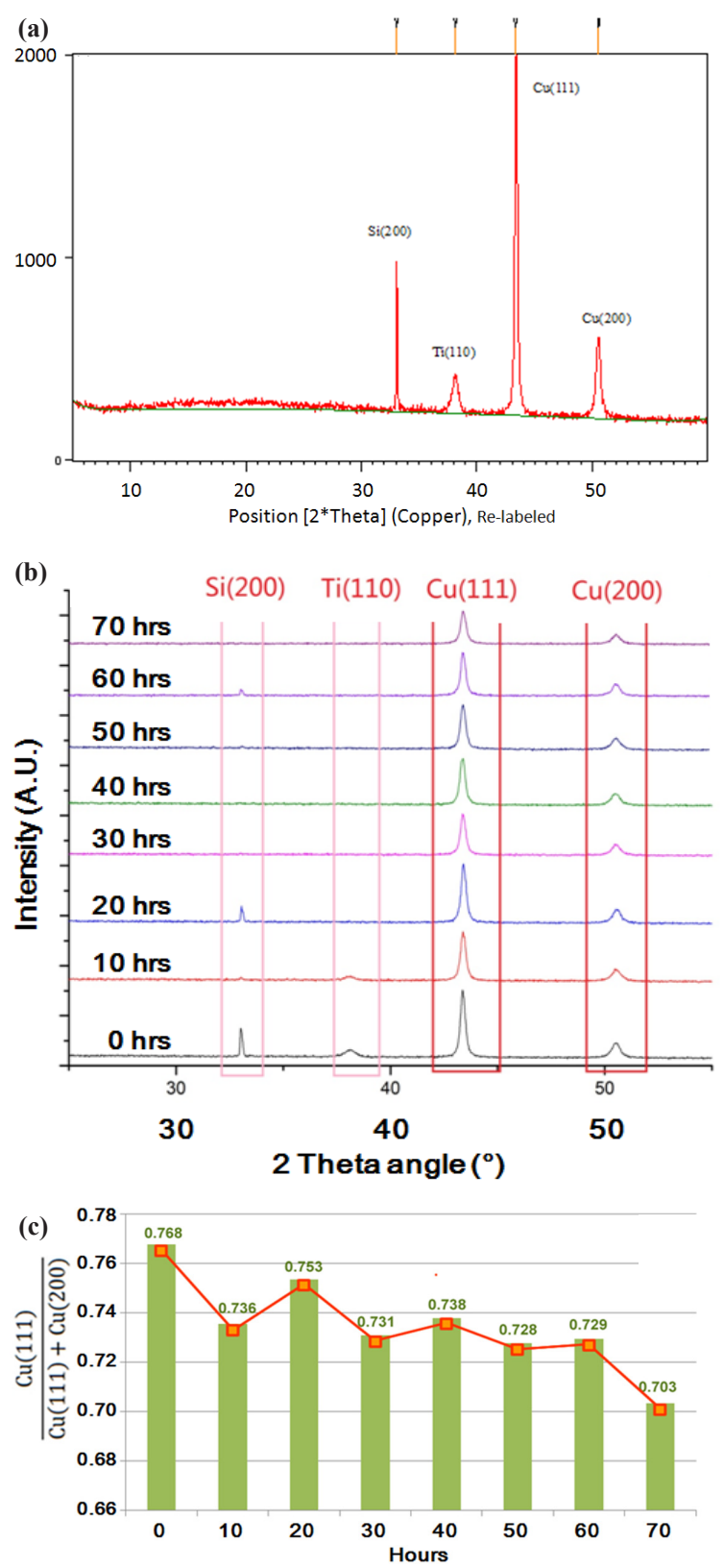

Fig. 9. The result of XRD analysis; (a) sample XRD data and (b) the ratio of $\mathrm{Cu}(111)$ to $\{\mathrm{Cu}(111)+\mathrm{Cu}(200)\}$.

cally deposited copper layer in Fig. 8(c) may show some amount of delamination because no adhesion layer was used for the silicon-copper interface. Otherwise, our CED process was generally successful. We also measured the thickness of the deposited copper at 10 and 20 hours, and the measured thicknesses were gradually decreased to 1.78 and $1.68 \mu \mathrm{m}$. The decrease in deposited thickness agrees with the degradation of the bath in the redox process, which is represented in color change of the hydrate sulfate solution.

Metal grain structure is also a critical factor for copper as a semiconductor interconnection material. (111) $\mathrm{Cu}$ has better electromigration resistance than (200), and the (111)/(200) ratio is inversely proportional to the amount of impurity in electrochemically deposited copper. To examine the film quality of a deposition, we presented the intensity ratios of $\mathrm{Cu}(111) /\{\mathrm{Cu}$ $(111)+C u(200)\}$ from the XRD measurements in Fig. 9. The wafer samples were measured with XRD analysis every 10 hours, the results of which were shown in Fig. 5(a). Surprisingly, the ratio decreases along with the process time, and this trend is well matched with optical monitoring results as shown in Fig. 6(b). The sudden drop of the ratio seems to correlate well with the saturation of observed in optical transmittance spectroscopy shown in Fig. 7(b).

It is desired to analyze the preferred orientation of the deposited metal thin layer in the same thickness because of the grain growth mechanism. Random nucleation allows a variety of growth orientations in the beginning of deposition process, and the grains with lower surface energy or higher growth rate (which is (111) in $\mathrm{Cu}$ deposition) becomes dominant. It is possible for (111) grain fraction over (111)+(200) to be decreased due to the reduced thickness of the deposited material. Unfortunately, we have not performed detailed material research regarding the amount of impurity in the solution vs. electrical characteristics, but further detailed material characterization such as resistivity measurement still remains for in-depth correlation research.

\section{CONCLUSIONS}

Optical monitoring methods including chromatic monitoring and optical transmittance spectroscopy were demonstrated used for in-situ real-time monitoring of the electrochemical copper deposition process. Process variables to be controlled in the process are numerous, and the condition of the chemical solution in a plating bath is one of them. Conventional monitoring of chemical solution relies on the $\mathrm{pH}$ value of the solution, electrical voltage level by oxidation-reduction, and gravity measurement by immersing sensors into a plating bath. However, we employed an optical non-intrusive monitoring technique using three types of optical process monitoring tools, such as chromatic sensors and UV/VIS/NIR spectroscopy to develop a technically feasible optical monitoring method. This research is motivated by the fact that as the concentration of the copper cations $\left(\mathrm{Cu}^{2+}\right)$ is reduced during the electrochemical deposition process, the deposition rate becomes lower, thus deposition rate and film quality are affected by the condition of the solution in the plating bath. Employing in-situ monitoring sensors, we observed that the chromatic information, especially Hue $(\mathrm{H})$ and Saturation (S) from the RGB sensor, presents strong correlation with deposition rate along the length of time of the process. The reduced intensity of the fraction of (111) $\mathrm{Cu}$ grains with increasing processing time in XRD analysis correlates well with the increased impurity concentration in the bath. Process modeling employing advanced algorithms is currently under investigation, and much of the meaningful work on the optically-acquired data analysis can be expected soon.

\section{ACKNOWLEDGMENTS}

The work was supported by a 2011 research fund from Myongji University in Korea, and the authors are grateful to the staff and members of the Semiconductor Process Diagnosis Research Center. Special thanks to Mr. Seungnam Son for providing TSVetched wafers, and Mr. Sang Hyun Chun serving as a Fab manager while this research was performed.

\section{REFERENCES}

[1] P. C. Andricacos, C. Uzoh, J.O. Dukovic, J. Horkans, and H. Deligianni, IBM Journal of Research and Development, 42, 567 (1998) [DOI: 10.114/rd.425.0567]. 
[2] R. Beica, C. Sharbono, and T. Ritzdorf, Proc. 58th Electronic Component and Technology Conference, 577 (2008) [DOI: 10.1109/ECTC.2008.4550031].

[3] J. Reid, V. Bhaskaran, R. Contolini, E. Patton, R. Jackson, E. Broadbent, T. Walsh, S. Mayer, R. Schetty, J. Martin, M. Toben, and S. Menard, Proc. Int. Intercon. Technol. Conf., 284 (1999) [DOI: 10.1109/IITC.1999.787145].

[4] C. Ryu, K.-W. Kwon, A.L.S. Loke, H. Lee, T. Nogami, V.M. Dubin, R.A. Kavari, G.W. Ray, and S.S. Wong, IEEE Trans. Elect. Dev., 46, 1113 (1999) [DOI: 10.1109/16.766872].

[5] H. P. Feng, M. Y. Cheng, Y.L. Wang, S. C. Chang, Y. Y. Wang and C. C. Wan, Thin Solid Films, 498, 56 (2006) [DOI: 10.1016/ j.tsf.2005.07.062].

[6] S,-i. Imai and M. Kitabata, IEEE. Trans. Semi. Manufac., 22, 432 (2009) [DOI: 10.1109/TSM.2009.2031757]

[7] C. Gabrielli, P. Mocotéguy, H. Perrot, D. Nieto-Sanz, and A Zdunek, J. Appl. Electrochem, 38, 457 (2007) [DOI: 10.1007/ s10800-007-9459-1]
[8] S. Imai, M. Kitabata, and T. Tanaks, Proc. Adv. Semi. Manufac. Conf., 254 (2009) [DOI: 978-4-9904138-2-8].

[9] S. Imai and M. Kitabata, IEEE Trans. Semi. Manufac., 22, 432 (2009) [DOI: 10.1109/TSM.2009.2031757].

[10] S. Hong and G.S. May, IEEE. Trans. Semi. Manufact., 17, 408 (2004) [DOI: 10.1109/TSM.2004.831952].

[11] H. Namkung, Y. Lee, and H. Chung, Analytica Chimica Acta, 606, 50 (2008) [DOI: 10.1016/j.aca.2007.10.047].

[12] T. Sato, Y. Ozaki, and K. Iriyama, Langmuir, 10, 2363 (1994) [DOI: 10.1021/la00019a055].

[13] J. A. Mielczarski and E. Mielczarski, J. Phys. Chem., 99, 3206 (1995) [DOI: 10.1021/j100010a035]

[14] J. R. Petherbridge, P. W. May, G. M. Fuge, K. N. Rosser, and M. N. R. Ashfold, Diamond and Related Materials, 11, 301 (2002) [DOI: 10.1016/S0925-9635(01)00576-3].

[15] S. Hong and G. May IEEE Trans. Industrial Electronics, 52, 1063 (2005) [DOI: 10.1109/TIE.2005.851663]. 